are aiming to peck. Birds' larger-scale feats include long-distance migration and homing, still mysteries in many ways but controlled at least partly by vision, and long-lasting memories for locations of stored food by titmice, nutcrackers and a few other species. Finally, the fact that complex visual behaviour has evolved in a group widely separated from the betterstudied mammals raises important comparative questions about the way in which anatomically and phylogenetically distinct

\section{IMAGE UNAVAILABLE FOR COPYRIGHT REASONS}

\section{A male satin bowerbird ( $P$. violaceus)}

species have solved their common problems of interacting with the visual world.

Most laboratory work on the adult avian visual system and visually guided behaviour has used the readily available and robust pigeon. Indeed, 'pigeon' is omitted from the index of species names in the book on the grounds that almost every chapter mentions this animal. From work on pigeons, and the almost equally popular domestic chicken, one can learn the answers to questions applicable to many avian species. Why do some birds bob their heads when they walk, rather than moving them smoothly forward in line with the body? How does an animal with eyes on the sides of its head integrate information from separate visual fields?

Attempts to answer such questions have produced some surprises. For example, not only does information from the lateral visual fields not readily transfer from one hemisphere to the other, but in some cases there may also be hemispheric asymmetry, with one 'eye system' specialized for spatial and the other for object-specific information. In chicks, this lateralization develops as a consequence of the embryo's position in the egg.

This book covers almost every aspect of vision and visually guided behaviour in birds, from the structure of the eye, colour vision and the functional and developmental anatomy of the visual system, to prey capture by herons and kingfishers, laboratory tests of visual-concept discrimination and the neurobiology of homing and spatial memory. All 22 chapters are written by experts in their fields. Although the coverage is broad, the volume does not pretend to be encyclopaedic. Rather, each chapter is a clear and well-organized introduction to a particular topic, while the extensive and largely up-to-date reference lists can lead the reader into greater depth. Anyone studying vision in species other than birds is likely to find material of comparative interest here, and the book should be read from cover to cover by students of any aspect of bird behaviour or brains. Those studying birds' visually guided behaviour will become more aware of their subjects' visual capabilities, such as some species' possession of ultraviolet sensitivity and two foveas; and those investigating basic visual processes in birds will learn more about what their subjects may be using vision for.

Sara J. Shettleworth is in the Departments of Psychology and Zoology, University of Toronto, Ontario, Canada M5S 1 A1.

\title{
Vulcans, terminators and science
}

\section{Harry Kloor and Dennis Harp}

\section{Fantastic Voyages: Learning Science Through Science Fiction Films. By Leroy W. Dubeck, Suzanne E. Moshier and Judith E. Boss. American Institute of Physics/Oxford University Press: 1994. Pp. 327. \$40, £25.}

SCIENCE fiction has an enormous influence on young people's perceptions of science and scientists. So it seems sensible to use it as an aid in teaching science. The thread tying science to science fiction forms the fabric of Fantastic Voyages, a science literacy text for nonscientists.

Only abbreviated descriptions of the principles of physics and biology can be presented in such a book. Although most of the coverage of science is easy to read, it is rather dry and will probably entertain only the most dedicated reader. But the physics section does include helpful and sometimes humorous accounts, and nonscientists will be thrilled to learn that it is 99.9 per cent formula-free; readers will obtain a basic grasp of Newton's laws of motion, special relativity, diffusion and thermodynamics. Certain chapters are scientifically weak though, most notably those on electricity and magnetism and evolution, and the accuracy of complex concepts is often compromised by oversimplification.

The essence of the book lies in the illumination of science through selected films, but instead of using the rich archive to provoke an interest in the wonders of science, the authors have allowed stodgy and overly critical analysis to prevail. Although undeniably a matter of taste, admirers of science fiction will on the whole be disappointed, and many wouldbe followers of science will be turned off by the 'righter than thou' approach.

In many of the examples the physics author seems to have missed the concep- tual boat. For instance, when Yoda uses his mind to lift a spacecraft in The Empire Strikes Back, he is trying to control an etheric, perhaps omnipotent substance that pervades all creation, rather than generate all the energy involved himself. And because Superman is often shown carrying an immensely heavy object while flying, why can't he support one without it pushing him through the rocks on which he is standing?

Nevertheless, the idea of using science fiction films to convey science in an interesting way is sound, and anyone preparing a course using the genre should at least consult this book.

Harry T. Kloor and Dennis Harp are in the National Science Outreach Program, Purdue University, West Lafayette, Illinois 47907, USA.

- Aficionados and newcomers will find both literary and scientific inspiration in The Norton Book of Science Fiction edited by Ursula K. Le Guin and Brian Attebery (Norton, $\$ 27.50$, £22). This 869-page anthology contains 67 stories by North American writers published between 1960 and 1990. In her introduction, Le Guin argues that science-fiction cannot be judged purely on the merits of its scientific content: "there are serious and beautiful science-fiction stories in which the science is completely imaginary and the technology not only implausible but impossible. . . The great boondoggle, popularly and accurately known as 'Star Wars', is an instance of governmental sci $\mathrm{fi}$ - a rationally conceived but technologically absurd program based on wishfulfiliment".

\section{Correction}

A typographical error crept into the review of Chromosomes: A Synthesis in last week's issue (Nature 368, 26; 1994). The reviewer's name is Joy Delhanty. Our apologies for the mistake. 